\title{
EFL Students' Perception on the Use of Debate in Speaking Classroom
}

\author{
Andini Amaylia Putri ${ }^{1}$, Rojab Siti Rodliyah ${ }^{2 *}$
}

\author{
${ }^{\text {ISDIT Al Fath }}$ \\ ${ }^{2}$ Universitas Pendidikan Indonesia \\ ${ }^{*}$ Corresponding author. Email: rojab@upi.edu
}

\begin{abstract}
Speaking is one of the skills to master in any language learning. In EFL context, mastering speaking skills can be challenging due to the limited exposure to the target language and chance to use it in a real communication. Therefore, teachers need to choose appropriate techniques in their speaking class to help students improve their speaking skills. One of the techniques to improve speaking skills is using debate. This study aimed to investigate how EFL students perceived the use of debate in Speaking classroom. A total of ten EFL college students participated in this study. The students experienced debate in the fifth semester, where they were given a chance to experience a debate practice in Speaking classroom. A questionnaire and an interview were administered to obtain the data on students' perception. The findings revealed that students held a positive perception on the use of debate since it helped them to express their opinion verbally, reduce speaking anxiety, improve their confidence and make them prepare speech systematically. This study suggests that debate can be conducted in a speaking class as an alternative to enhance EFL students' speaking fluency.
\end{abstract}

Keywords: Debate, EFL students, Speaking classroom, Speaking fluency, Students' perception

\section{INTRODUCTION}

In Indonesia, English serves as one of the foreign languages that has been taught from elementary school to university (Arung, 2016). However, despite the fact that Indonesian EFL learners have been studying English for several years, when it comes to speaking, they do not seem to have developed good fluency. They were passive in speaking especially if the teacher asked them about their opinions and responding to other's opinions because they did not know how to deliver their opinions or their arguments (Desita, Supardi, \& Suhartono, 2017).

Speaking fluency is defined as the use of language quickly and confidently, with limited hesitations, unnatural pauses, and others. (Baily, 2010). Speaking fluency can be counted as a measurement of a person's communicative proficiency level; it also becomes a goal for EFL language learner (Yang, 2014). However, many Indonesian EFL learners still have difficulty in the communicative interaction (Marzuki, Prayogo, \& Wahyudi, 2016). Most of them tried to speak English but then got stuck in the middle because they cannot deliver their ideas easily in English; in consequence, they chose to use their native language to continue delivering their ideas (Juhana, 2012).
This is when fluency is needed. Even when learners have hard time to deliver their ideas while speaking, they can still speak the sentence with some fluency (Crowther et al., 2015). In developing fluency, there must be a supporting activity which has some specific features to improve speaking skills. The activities should focus on meaning, contain students' previous activity, and be challenging for students. Challenging means that the activities should trigger students' hard work, and it can be obtained through arranging limited time and pressure (Nation \& Newton, 2009). Those characteristics could be found in debate. Therefore, applying debate as a technique in enhancing students' speaking fluency might help the students in giving response to another's opinion (Desita et al., 2017).

Some studies have investigated the effect of using debate as a technique to enhance speaking ability (Arung, 2016; Desita et al., 2017; Elmiyati, 2019). However, few studies focus mainly on the speaking fluency and lack exploration in how students perceived the use of debate in Speaking classroom. Moreover, most previous studies focused on the implementation of the debate technique in Senior High School level. Thus, this study explores university students' perceptions toward the use of debate 
and how it helps their speaking fluency. After investigating the students' perceptions, the adjustment can be made to improve the selected methods and students' speaking ability.

\section{LITERATURE REVIEW}

\subsection{The concept of perception}

Perception can be defined as the process of receiving or understanding information in a more detailed way. From the cognitive dimension of perception, perception is the process by which people attach meaning to experiences (Eggen \& Kauchak, 1988). Perception also refers to the process of selecting, organizing, and interpreting stimuli conducted by someone to get a coherent and meaningful picture of the world (Kumar, 2010). People who are being exposed to a situation or a stimulus, they will receive the information meaningfully based on their previous experience (Gould, 2014). All perceptions involve signals passing through the nervous system resulting from physical or chemical sensory system stimulation. It depends on complex functions of the nervous system but on the other side it all seems effortless because this process happens outside conscious awareness (Goldstein, 2009). However, perception is not a passive process of those signals; later it is going to be shaped by the recipients' memory, expectation and attention.

\subsection{The concept of speaking}

Speaking is a process of constructing meaning which involves producing, receiving and processing information (Burns \& Joyce, 1997). By speaking, people are able to discuss, criticize and do other ways of interaction (Nuraeni, 2014). For English as a second language (ESL) and English as a foreign language (EFL) students, mastering speaking is the most essential aspect of learning a new language. Success can be achieved if someone has the ability to carry out a conversation (Nunan, 1995). The students are often afraid if they are making mistakes in producing speech so the message cannot be achieved (Nuraeni, 2014). In carrying out speaking, the students may be nervous and perform poorly on their learning process because of cognitive or first language disabilities or both (Horwitz, 2000). They need to consider some things before speaking, such as deciding what they want to say, choosing the words that they are going to use, choosing the words into pattern that carries the meaning of it, using correct composition of word, making sure the appropriate situation, and placing lips and tongue in certain position to produce sounds.

\subsection{The concept of fluency}

The term of fluency is linked to the meaning of communication (Harmer, 2010). For example, in a conversation, learners can make a grammatical error, but they can still speak the sentence with some fluency (Crowther et al., 2015). The learner delivers their thoughts without pausing to search words to make his or her speech understandable. In fact, speaking fluency is defined as the automaticity and speed of speech production (Brand \& Götz, 2011). However, regarding the automaticity and speed of speech production, it may not always make a speech comprehensible and one of the measure of listeners' perceived ease or difficulty of understanding L2 speech is comprehensibility (Crowther et al., 2015).

Fluency development is one of the main goals of formal language instructions. However, the development of fluency is sometimes not successful due to the lack of exposure to the language (Mora \& Valls-Ferrer, 2012). For this reason, the teaching techniques and activities should have some specific features to help students in developing speaking fluency. They must focus on meaning, take into account the previous experiences of students, and be challenging for the students by giving limited time and pressure (Nation \& Newton, 2009).

After all, it is necessary to explain the relation between the two concepts of speaking and fluency. Speaking is the main skill, and it includes all the levels of speaking communication and all the stages of the process. On the other hand, fluency is a sub-skill and implies how easy a foreign language learner can express himself without having to stop to think about words and experience breakdown in communication (Barios, 2017).

\subsection{The concept of debate}

In a classroom, teachers can develop some aspects of speaking, but not necessarily fluency. That is why it is relevant to create effective techniques to develop fluency in English speaking production within a classroom. In this case, debate in a classroom is the technique that is investigated by the researchers to understand whether or not the technique helps students in enhancing their speaking fluency.

Debate is an activity involving two groups of people on opposite sides discussing a topic with certain rules. There are judges to assess both sides of the arguments and choose the winning team based on the reasoning and evidence provided. They have to stand against opposite teams' point of views and arguments (Ristawati, 2019). 
Additionally, debate motivates students to think from different points of views about an issue. Students have a chance to utter their ideas not only about the given topic, but also with one another (Halvorsen, 2005).

\section{METHOD}

\subsection{Research Design}

The ultimate purpose of this study is to know students' perceptions on the use of debate in enhancing speaking fluency of the students. This qualitative study employed a questionnaire and interview to obtain the data.

The participants of this study were sixteen students who had taken Speaking for Academic Purposes subject in one public university in Indonesia. They were selected using a convenience sampling (Saunders, Lewis, \& Thornbill, 2012) to suit the aim of the study. They had experienced English debate during the course. Ten participants were given the questionnaire meanwhile six were involved in the interview. Despite the subjectivity because the researchers rely on their own judgment when choosing members of the population to participate in the study, this was taken with careful consideration, considering that the selected participants met the profile needed for this study.

\subsection{Data Collection}

This study used questionnaire and interview to collect the data from the participants. The researchers collected the data by using the Google forms and voice note. The questionnaire was distributed first to the students by sharing the Google forms link to the classroom' group chat meanwhile the interview was followed afterwards.

\subsubsection{Questionnaire}

The purpose of the questionnaire was to gather information on how students' perception on the use of debate. The questionnaire was the most suitable tool to acquire information on participants' perceptions, social characteristics, present and past behaviour, standards of behaviour or attitudes and their beliefs and reasons for action with respect to the topic under investigation.

Due to the global pandemic Covid-19, the researchers distributed the questionnaire to the students by using Google form. The questionnaire was adapted from Wulandari (2017) and was distributed in one section. Ten close-ended statements were assessed using a four-point Likert scale to show the agreement of their experience in using debate to affect their speaking fluency.

\subsubsection{Interview}

An interview is a flexible instrument in the research field because the interviewer has a freedom to observe the subject as well as the situation in which the subject gives the responses (Wulandari, 2017). Moreover, it enables the researchers to gain large volume of in-depth data in a relatively short time (Ary, 2010). it is important to allow the researchers to achieve the data that are not collected through written documentation. In this study, the interview consists of nine questions which the students had to answer based on their opinions toward the use of debate in enhancing speaking fluency. In this study, the interview was used as the second tool to further analyse the respondents' answers in the questionnaire to get a clear opinion or information and to avoid misunderstanding. Furthermore, the researchers obtained the data from the interview by using voice notes. Meanwhile, for the interview the researcher used questions list as a guideline to keep the plot of the interview still on track.

\subsection{Data Analysis}

\subsubsection{Questionnaire}

For the questionnaire, the researchers analysed participants' responses on ten close-ended statements about their experience in doing the debate. The responses were calculated in percentage to illustrate how debate affects their speaking fluency. Then, the researchers made a description analysis based on each statement from the questionnaire after calculating the percentage results. Meanwhile, the interview consisting of nine open-ended questions related to students' perspectives on how debate helps/not helps them in enhancing their speaking fluency. The data from the interview were transcribed and analysed to describe the findings. Voice notes were used to obtain the data and save them in order to make a transcript and using a question list as a guideline to keep the plot of the interview still on track.

\section{FINDINGS AND DISCUSSION}

\subsection{Students' perception about the use of debate in speaking class}

This study revealed that majority of students have positive perception regarding the use of debate. They think that debate helps them express their opinion verbally, is an enjoyable activity, and improves their speaking fluency. However, there are also some negative views regarding the use of debate, such as the difficulty in expressing the ideas in a debate, much time needed, and difficulty in keeping up with others. 
The findings from questionnaire indicated that students have positive perception about the use of debate. This can be seen from the students' response to the questionnaire with Likert scale (1: strongly agree, 2: agree, 3: disagree, 4: strongly disagree) as follow:

\subsubsection{Debate helps students express their opinion verbally}

The majority of students $(80 \%)$ stated that debate helps them express their opinion verbally. This can be seen in Figure 1. Based on the above data in Figure 1, it can be concluded that most of the students agreed that debate helps them in expressing their opinion verbally. As two students chose Strongly Agree (20\%) and eight students chose Agree (80\%). After doing a debate practice, they felt that it helps in releasing all of their personal idea or thoughts regarding to the topic of the debate, and it all can be conveyed verbally.

\subsubsection{Debate is an enjoyable activity}

In addition to helping students express their opinion verbally, debate is also considered to be a good activity to help students improve their speaking ability. From the data in Figure 2, it can be seen that one student chose Strongly Agree (10\%) and seven students chose Agree (70\%) to the statements. Most of the students enjoy the debate, only $20 \%$ of them did not enjoy the activity.
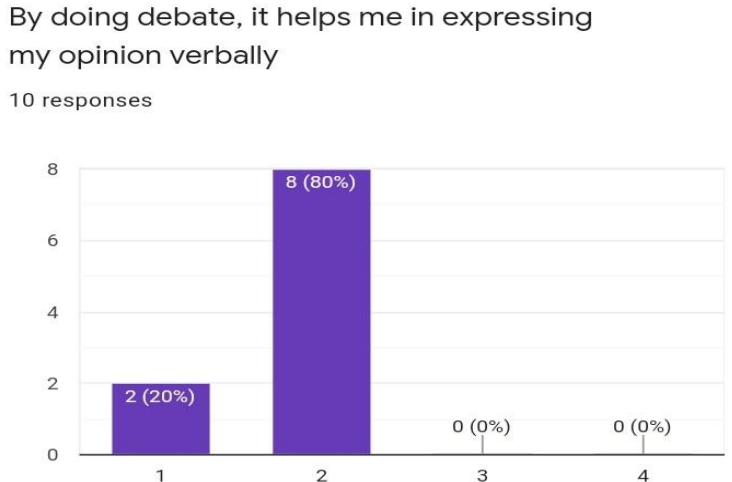

Figure 1 Questionnaire results of students' perception whether or not debate helps the students in expressing their opinion verbally
10 responses

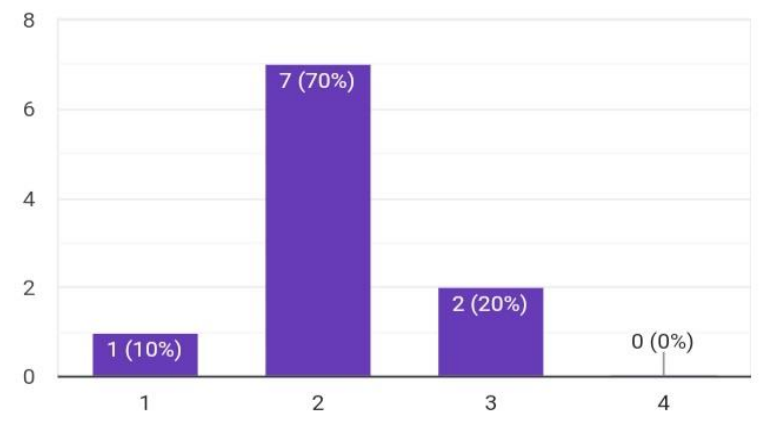

Figure 2 Questionnaire results of students' perception whether they are enjoying the practice of debate in the class

\subsubsection{Debate helps students improve their fluency}

The participants also perceived that debate helps them improve their fluency as shown in Figure 3. Six students chose Agree (60\%) to the statements. They felt that debate helps them in enhancing their speaking fluency. Nonetheless, four students (40\%) argued that even after doing the debate practice, they did not feel that it has affected their speaking fluency.

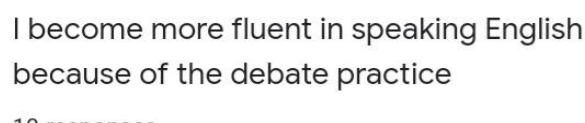

10 responses

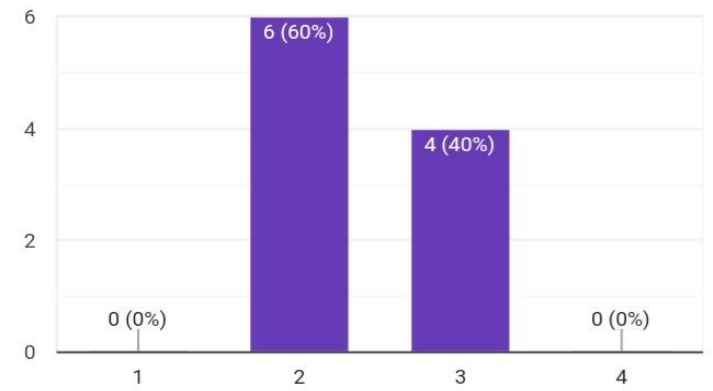

Figure 3 Questionnaire results of students' perception whether they think debate affects their speaking fluency 
This is also supported by the results of the interview in which the respondents said that debate could be one of the effective ways to enhance speaking fluency. However, some of them argued that debate is not the only way to enhance speaking skills, especially fluency. There are many other methods other than debate. What makes debate meaningful to them is through debate they can practice speaking skills in a formal situation. Some of them complained about the rare opportunity to speak formally, especially to their friends so they used this opportunity to challenge their selves to speak in formal situations that require them to express their opinions and ideas well. As one of the students said:

"I am sure there are a lot of good methods out there that are more effective than debate, but in my opinion, debate can be used as an alternative to improve speaking skills. One of the reasons is because the most common difficulty that people usually faced whenever we want to speak in a foreign language is that we do not believe in ourselves. Through debate, we are required to deliver our arguments, thoughts, or opinions in a formal context so regardless of our lack of confidence in speaking, we have to overcome it and just do the debate."

Furthermore, the majority of the students claimed that they felt a change in their speaking fluency. One student added the thing that influenced their improvement of speaking fluency happened at the time when she was practicing the arguments with her teammates before the debate began. That is when she felt a change has occurred to their speaking fluency the most. The other student added that she felt a change in her speaking fluency when debate assists her to overcome her anxiety. She can deliver her arguments smoothly without worrying about other things but her arguments. This is in line with the rest of the students' opinions, a change has happened to their confidence so they can speak well in front of others without pausing or worse, forgetting their arguments. They stated that they can speak fluently if they can fight over their anxiety, lack of confidence and nervousness. If those things were solved, then they were sure there would be no other barrier for them to have a good speaking fluency.

\subsubsection{Debates is not easy to do}

The participants think that they have some difficulties during the debate practice.
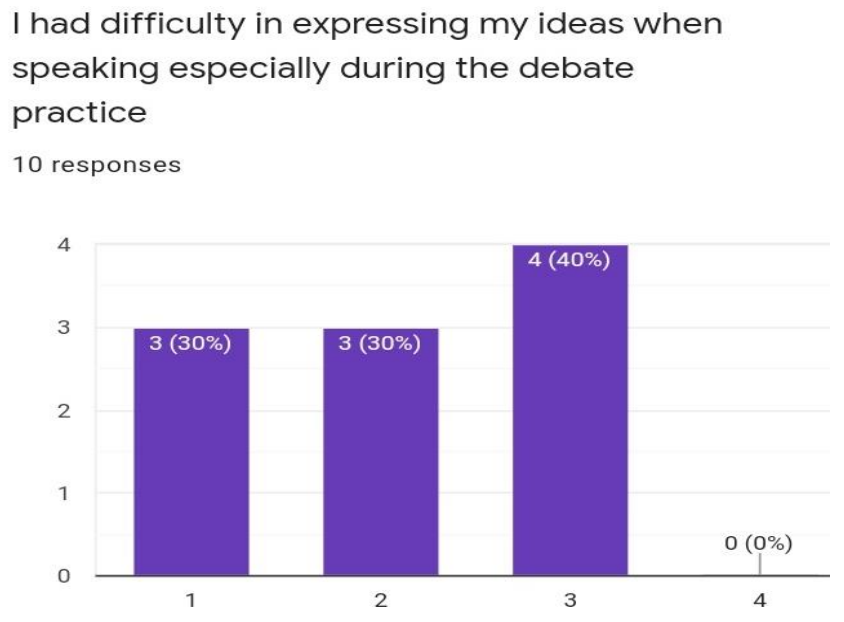

Figure 4 Questionnaire results of students' opinions on the problems during the debate practice

Looking at the above data, three students chose Strongly Agree (30\%) and three students chose Agree $(30 \%)$. It means most of them found any kinds of difficulties during the debate practice. The kind of difficulties that they faced were revealed from the interview result. On the other hand, four students chose Disagree (40\%), meaning that they did not find any difficulties in delivering their ideas during the debate practice.

\subsubsection{Debate requires more time to prepare}

Debate is considered to be time consuming because students need extra preparation time to find the ideas and arguments from their debate. Figure 5 shows the students' approval towards the use of time in debate. Eight students chose strongly Agree (80\%) and two students chose Agree (20\%) that they need more time to prepare all the needs for the debate practice. They cannot simply just come and does a debate practice without preparing the outlines and organizing other things. 


\author{
I need more time to prepare the outlines \\ before delivering the \\ arguments/statements \\ 10 responses
}

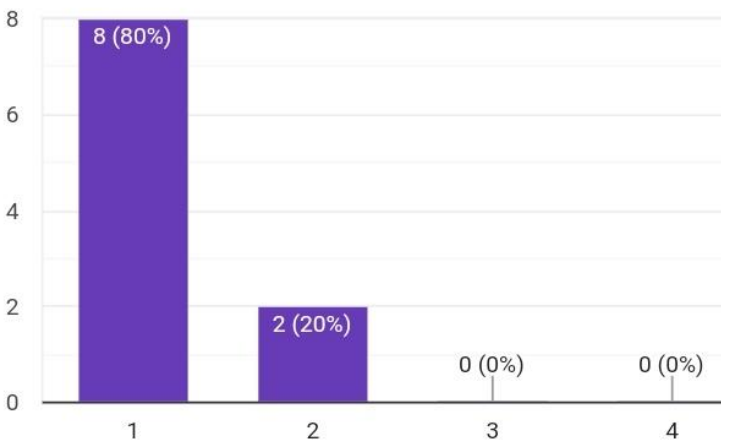

Figure 5 Questionnaire results of students' opinions whether they need more time to prepare the arguments/outlines before the debate begin

\subsubsection{Debates requires students to think quickly}

In debate, the flow of the speech should be conducted quickly and that makes some students think that they have difficulty keeping up with others. Based on Figure 6, half of the students agreed that in the practice of debate sometimes they cannot keep up with others. Meanwhile the other half did not experience anything that causes them to lose the pace or cannot keep up with others. This is also supported by the results of the interview in which the respondents said that they felt nervous, clueless and uninterested because they know nothing about debate. One respondent mentioned that she just barely knew that there were so many rules in debate, and she did not expect that. Besides, they also said that they were not good at speaking; this caused them to learn even harder in order to cope up with others in debate.

Moreover, two respondents stated that the difficulty of practicing the debate lies in preparing the data and the arguments related to the topic. Even when the lecturer gave them some time to look for some supporting data, sometimes, they felt that it is still not enough. She said:

"When the opponent gives an argument, which is difficult for us and we don't prepare the data. That is a major difficulty in the debate itself".

\section{In the debate practice, sometimes I can't keep up with others \\ 10 responses}

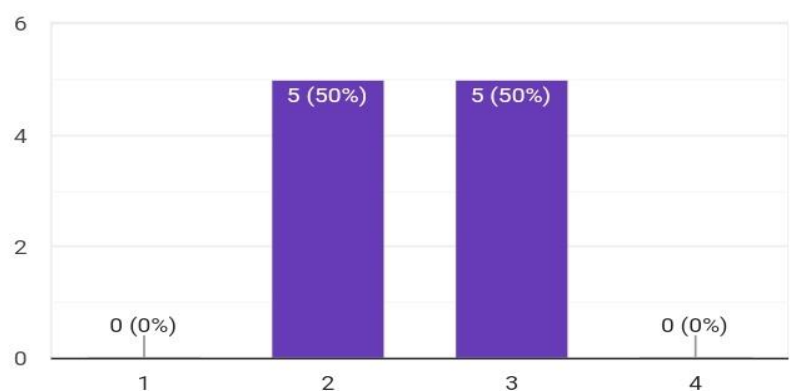

Figure 6 Questionnaire results of students' opinions whether they can keep up with other students in the practice of debate

One of them added the fact that they found it hard to decide the first, second and third speakers. On the other hand, some students argued that the main problem is still on their speaking skills as one of the students claimed:

"For the difficulty that I faced during the debate practice is still about speaking. I'm not a person who is good neither at speaking nor the type of person who is easy to express my opinion verbally. So, yeah it's all about my speaking ability".

\subsection{How debate helps enhance speaking fluency}

According to the students, debate enhances their speaking fluency in several ways.

\subsubsection{Debate develops students speaking and reasoning skills}

Majority of the students said they could not speak fluently due to the lack of opportunity for them to speak English outside of the class. Sometimes, the students are afraid if their opinion is not very helpful whenever someone asked their perspectives regarding to a problem. That makes them even more hesitant to express their opinion. Through debate, they have the opportunity to practice their speaking fluency. Especially, in a formal context that needs a proper preparation because it is different from a casual conversation which can happen anytime. In debate, the students felt that their personal opinions are needed. They are required to stand firm to their opinion regardless of their fear that their opinion is not going to make any changes. Also, they have to deliver their opinions out loud in front of others. Those things 
helped the students to share their opinion verbally without worrying about other things but their opinion. Their reasoning skill is also improved since students need to give reasonable argument during debate. Thus, they also practice their higher order thinking skill by being critical towards an issue being debated.

\subsubsection{Debate helps students to overcome their anxiety}

Some students said they have several problems that could influence their speaking fluency, one of them is speaking anxiety. They are worried about making errors, especially grammatical errors. Whenever students feel anxious, the things that they are going to say cannot be accepted well (Agustina, 2019). Actually, anxiety is not a new thing in EFL students' context, some EFL students feel extremely anxious because they found it quite difficult to control their nerves, those facts clearly affect their speaking performance and the outcomes very often become a mess. Through debate, some of the students said it helps them to control their anxiety because there are few practices before the debate began. At that time, they learnt to deliver their arguments in front of their teammates which have a good impact for their anxiety problem. They are getting used to that kind of activity so when the time has come for them to speak in front of the class as their team's representative, they can overcome their anxiety problem slowly but surely.

\subsubsection{Debate improves students' confidence}

Some students said besides speaking anxiety, the other problem that they found whenever they have to speak in front of other people is the lack of confidence. During the debate preparation, a change has happened to their confidence. After several practices with their teammates, they began to feel a sense of confidence because they can deliver the arguments to their friends and the responses that they got is quite satisfying. So, they began to think that it is okay to be confident and just deliver their arguments, thoughts or ideas in front of others because their friends will not judge them even when sometimes they made mistakes. Students will gain confident if they are managed to handle various communication situations that they might encountered anytime. As stated by one of the respondents:

"Personally, I feel nothing has changed, maybe one thing that changes is my confidence level, that's all. During the debate, I felt more confident when speaking compared to the number of times I spoke before, but I do not feel a great change or effect from the debate activity to my speaking ability. But yeah, I had fun experiencing debate in speaking classroom"

\subsubsection{Debate makes students prepare speech systematically}

The responses from the interview section showed that debate also helped the students to make an outline before speaking. As the fact that speaker could generate their ideas by start writing an outline (Nicholls, 1999). Some of the students argued that they need to prepare an accurate data to support their arguments. They cannot just talk without providing the evidence towards their arguments. If they are doing that, it opens a huge chance for the opposite team to attack their team. Therefore, the students wrote an outline to help them in delivering their arguments comfortably. They also made some points to signify the man idea of their arguments. The students believed that by showing some data to the audience it can make them agree on their team's arguments. With an outline, they get a support system to speak fluently in front of others without any fear.

Based on the results of students' perception on the use of debate in the speaking classroom, the majority of the students agreed with the statements that said debate helps them in enhancing their speaking fluency. It also can be seen from the result of the questionnaire and from the interview. Thus, the researcher concludes that debate contributes positively to the improvement of students' speaking fluency.

Besides, the researcher found how debate helps them in enhancing their speaking fluency. Some students said it helps them in expressing their personal opinion verbally, reducing their speaking anxiety, improving their confidence and makes them prepare speech systematically. Those impacts are the results of students' involvement in the debate activities. If the students were given a chance to take part in a teaching learning process, it will encourage them to be confident to speak in English than before (Uswatun, 2012).

Nevertheless, some of the students shared another barrier that they felt during the implementation of debate. That is the time limit to prepare the data for the arguments. Some of them had a hard time in preparing the outlines due to the lack of experience on doing the debate. As a result, during the debate they could not answer some unexpected questions from the opposite team. However, they added that the solution of this problem is their speaking ability. By using their speaking ability, they can 
improvise even when the answer is not in the outlines that they have prepared. As debate can motivate students' thinking because they have to stand firm to their arguments regardless of their individual belief, current situation, etc. (Maryadi, 2008).

Debate in speaking classroom is aimed to enhance students' communication skill; by doing debate, students got a lot of chance to practice their speaking skills (Rubiati, 2010). At the same time, debate requires a proper preparation, teamwork, and making use of language functions such as: describing, explaining, giving and asking information (O'Malley \& Pierce, 1996). A proper preparation and practice are important to improve speaking skills (Fujishin, 2009). Based on the result of this study and several explanations above, the series of preparation and practice of speaking can also affect students' fluency. Therefore, the use of debate might be very helpful in contributing to make an improvement on students' speaking ability with a consideration to give the students an opportunity to prepare and practice before the implementation of debate in the classroom.

\section{CONCLUSION}

The main purpose of this study is to find out EFL students' perception whether debate helps them in enhancing their speaking fluency or not. This study revealed that debate can be conducted in a speaking class as an alternative to enhance EFL students' speaking fluency. This activity offers some benefits such as helping the students in expressing their personal opinion verbally, reducing speaking anxiety, improving confidence and makes students prepare speech systematically. Besides, having students debate on certain topic indirectly leads them to improve their questioning, predicting, analysing, evaluating and forming opinions skills, which are included into critical thinking (Fisher, 2005). This is in line with the demand of the $21^{\text {st }}$ century education, where students are expected to have critical thinking skills as well as communication, collaboration, and creativity (Stauffer, 2020).

Furthermore, the findings reported that students believed they can improve their speaking fluency through debate. Some students claimed it can help them overcome their anxiety, nervousness and the lack of confidence in speaking. Based on students' perception, they agreed that debate can help them in enhancing their speaking fluency. Even though other methods might also work to enhance speaking fluency, they said that debate is helpful to improve their speaking skills.
Debate has also taught them to speak with an evidence to support their arguments. They cannot speak anything without supporting data to strengthen their arguments. This also teaches them to become a good speaker who speak with a strong argument. Thus, debate trains them to think critically before presenting their arguments.

As debate can enhance students' speaking skills, it is suggested that English teachers could apply this method in their learning activities. English teachers need to understand the whole concept of debate, how the debate goes, what are the rules of debate, which kind of debate style which is suitable for the students. They can talk about the current issue around the environment to attract students' attention, so they are willing to explore the topic by themselves out of curiosity. This research has limited number of participants. Thus, future studies should involve more participants to gain more comprehensive data on the use of debate. Besides, this research does not use observation to get the portrayal of how the debate is being implemented. Future studies should conduct observation to gain a deeper insight on how the debate can be implemented. Lastly, this research only looks at the use of debate from students' perspective. Future studies can investigate it from the teachers' point of view.

\section{REFERENCES}

Arung, F. (2016). Improving the students' speaking skill through debate technique. Journal of English Education, $\quad$ 1(1), 70-76. doi: 10.1016/j.ecoleng.2009.03.005

Agustina, D. (2019). Students'perception of the jigsaw technique implementation in learning speaking at the first-grade of SMAN 7 Bandar Lampung. $U$ JET: Unila Journal of English Teaching, 8(3), 116.

Ary, D. (2010). Introduction to research in education. New York: Hort, Rinehart and Winston.

Crowther, D., Trofimovich, P., Isaacs, T., \& Saito, K. (2015). Does a speaking task affect second language comprehensibility? Modern Language Journal, 99, 80-95. doi: 10.1111/ modl.12185.

Desita, L., Supardi, I., \& Suhartono, L. (2017). Improving students' speaking ability through debate technique. English Education Study Program of FKIP UNTAN, Pontianak, 6, 5-9. 
Eggen P., \& Kauchak, D. (1988). Strategies for teachers: Teaching content and thinking skills. Englewood Cliffs: Prentice-Hall.

Fisher, R. (2005). Teaching children to think. Cheltenham: Nelson Thornes.

Fujishin, R. (2009). Smart public speaker: Seni berbicara di muka umum. Yogyakarta: Book Marks.

Gould, S. J. (2011). Full house. Cambridge: Harvard University Press

Goldstein, E. B. (2009). Sensation and perception. Belmont: Wadsworth.

Halvorsen, A. (2005). Incorporating critical thinking skills development into ESL/EFL courses. The Internet TESL Journal, 11(3), 1-5.

Juhana, J. (2012). Psychological factors that hinder students from speaking in English class (A case study in a senior high school in South Tangerang, Banten, Indonesia). Journal of Education and Practice, 3(12), 7-19.

Marzuki, M., Prayogo, J. A., \& Wahyudi, A. (2016). Improving the EFL learners' speaking ability through interactive storytelling. Dinamika Ilmu, 16(1), 15-34. doi: 10.21093/di.v16i1.307

Maryadi, A. (2008). Implementing debate in school. Jakarta: Rineka Cipta.

Mora, C., \& Valls-Ferrer, M. (2012). Oral fluency, accuracy, and complexity in formal instruction and study abroad learning contexts. TESOL Quarterly, 46(4), 610-641. doi: 10.1002/tesq.34

Nation, N., \& Newton, J. (2009). Teaching ESL/EFL listening and speaking. New York: Routledge.

Nicholls, A. (1999). Mastering public speaking: How to prepare and deliver a successful speech and presentation. Hongkong: Grolier Intl.
Nunan, D. (1995). Closing the gap between learning and instruction. Tesol Quarterly, 29(1), 133-158. doi: $10.2307 / 3587808$

Nuraeni, S. (2014). The effectiveness of classroom debate to improve students' speaking skilll (A quasiexperimental study at the elevent year student of SMAN 3 south Tangerang). (Unpublished bachelor thesis). Syarif Hidayatullah State Islamic University.

O’Malley, J. M., \& Pierce, L. V. (1996). Authentic assessment: Practical approaches for teachers. New York: Longman.

Ristawati, R. (2019). Student's perception on joining english debate program toward the student's critical thinking ability. (Unpublished bachelor thesis). Universitas Muhammadiyah Gresik.

Rubiati, R. (2010). Improving students' speaking skill through debate technique (A classroom action research with first semester students of English language teaching department tarbiyah faculty at IAIN Walisongo Semarang in the academic year of 2010/2011). (Unpublished doctoral dissertation). IAIN Walisongo.

Stauffer, B. (2020). What are the 4 C's of 21 th century skills? Retrieved from https://www.aeseducation.com/blog/four-cs-21stcentury-skills

Saunders, M., Lewis, P., \& Thornbill, A. (2012). Research methods for business students. London: Pearson Education Limited.

Wulandari, A. (2017). Students'perception on the use of debate activities in improving students'speaking skills in SMAN 8 Yogyakarta. (Unpublished doctoral dissertation). Sanata Dharma University. 